\title{
An Investigation on the Occurrence of Pathological Conditions Affecting Broilers in Jammu
}

\author{
Navroze Sanhga ${ }^{1}$, Shilpa Sood ${ }^{1 *}$, A.K. Taku ${ }^{2}$, Nawab Nashiruddullah ${ }^{1}$, Shafiqur \\ Rahman $^{1}$, Deep Shikha ${ }^{2}$, Satuti Sharma ${ }^{1}$ and Sankalp Sharma ${ }^{1}$ \\ ${ }^{1}$ Division of Veterinary Pathology, ${ }^{2}$ Division of Veterinary Micrbiology, Faculty of Veterinary \\ Sciences \& Animal Husbandry, SKUAST-J, RS Pura, Jammu, India \\ *Corresponding author
}

\begin{tabular}{|c|}
\hline Keywords \\
\hline $\begin{array}{l}\text { Occurrence, } \\
\text { Mortality, Poultry, } \\
\text { Diseases }\end{array}$ \\
\hline Article Info \\
\hline $\begin{array}{l}\text { Accepted: } \\
20 \text { July } 2019 \\
\text { Available Online: } \\
10 \text { August } 2019\end{array}$ \\
\hline
\end{tabular}

\section{A B S T R A C T}

The present study was carried out in the Division of Veterinary Pathology, FVSC\&AH, SKUAST-J R.S Pura, Jammu, to study the occurrence and mortality patterns associated with various pathological conditions in various parts of Jammu.200 flocks were surveyed in different areas in and around Jammu. Occurrence of colibacillosis $(24.16 \%)$ was maximum followed by that of infectious bursal disease (IBD) (7.13\%), omphalitis $(6.79 \%)$, salmonellosis $(5.36 \%)$. Other pathological or disease conditions found to be occurring in Jammu region were nonspecific enteritis (4.29\%), coccidiosis (2.22\%), haemorrhages in proven triculus $(1.67 \%)$, gout $(1.44 \%)$, nephro-hepatotoxicity $(1.42 \%)$, ascites (1.14), fatty liver syndrome $(1.03 \%)$, caseous nodules in lungs $(0.75 \%)$ and non specific liver ailments $(0.50 \%)$. The maximum mortality was caused by colibacillosis (8.33\%) followed by IBD (5.97\%), haemorrhages in proventriculus $(5.52 \%)$, omphalitis (4.54\%), salmonellosis (3.66\%).Nonspecific enteritis (3.36\%), nonspecific liver ailments (3.03\%), hepatotoxicity (2.95\%), caseous nodules in lungs (2.00\%), coccidiosis (1.69\%), ascites $(1.12 \%)$, gout $(0.77 \%)$ and fatty liver syndrome $(0.41 \%)$ were other major pathological conditions and diseases associated with mortality. On the basis of pathomorphological studies, bacteriological studies and parasitological examination, occurrence of various pathological conditions in broiler in Jammu was determined.

\section{Introduction}

Poultry production is an important agro-based enterprise of our country. India ranks third in broiler production in the world. Jammu and Kashmir $(\mathrm{J} \& \mathrm{~K})$ is a large meat consuming state, therefore, a rapidly developing broiler industry provides an excellent means for supplying quality meat and a good source of livelihood to the un-employed youth (Mehta et al., 2003).Morbidity and mortality due to various poultry diseases cause great economic losses to the farmers all over the world.Changing geo-climatic conditions, improper management practices and lack of awareness regarding biosecurity measures serve as major constraints for broiler industry and generally the aetiology of outbreak of diseases remains undiagnosed.Important infectious diseases of broilers are 
salmonellosis, colibacillosis, mycoplasmosis, coccidiosis, inclusion body hepatitis, New castle disease and avian influenza among others (Saif, 2008).

There is lack of documentation on various diseases and pathological conditions of broilers in Jammu, so this study was carried out to determine the occurrence of various diseases in Jammu.

\section{Materials and Methods}

\section{Study area}

The present investigation was carried out in the division of Pathology SKUAST-J R.S Pura to study the occurrence and mortality patterns of poultry diseases in various parts of Jammu. To achieve the envisaged objective of the research, a survey of 200 different poultry flocks in and around Jammu was conducted during the period July 2016 to June 2017.The study period was divided into four seasons as per Meteorological Department of India, Pune, viz., monsoon, post monsoon, winter and summer. Age wise and season wise disease occurrence and mortality pattern at the field level was determined. Occurrence of disease/pathological conditions and mortality pattern was determined as per the method described by Thrusfield (1995). Disease occurrence was calculated as per the formula given below:

Occurrence of disease $=$

Total no. of morbidity + Total no. of mortality $\times 100$ Total no. of birds in the flock

Mortality percentage was calculated as per the formula given below:

Mortality $(\%)=$

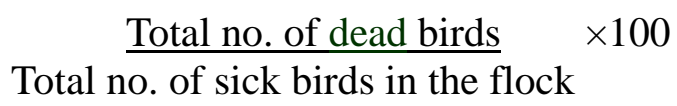

\section{Pathomorphological studies}

\section{Gross pathology}

Representative carcasses were necropsied from the mortality in different flocks. Postmortem examination of a total 632 birds was done. Systemic examination was carried out for the presence of any lesions in the GIT. Oesophagus, proven triculus, gizzard, pancreas, liver and intestine of dead birds were thoroughly examined and visible pathomorphological alterations were recorded.

\section{Histopathology}

After thorough gross examination, representative pieces of less than $5 \mathrm{~mm}$ thickness from respective visceral organs, viz., oesophagus, proventriculus, gizzard, liver, intestine and pancreas were collected in $10 \%$ neutral buffered formalin solution and processed for routine $\mathrm{H} \& \mathrm{E}$ staining (Luna, 1968).

\section{Bacteriological studies}

\section{Collection of tissue samples for bacterial isolation}

Liver and heart blood swabs were collected from representative dead birds aseptically into sterilized petri-plates. All the samples collected were processed on the same day.

\section{Isolation and identification of bacteria}

The organisms were identified on the basis of their morphological, cultural and biochemical characteristics. The procedure for isolation and identification of bacterial culture adopted for the present work was as per Cruickshank et al., (1975). The samples were inoculated in nutrient broth and kept at $37^{\circ} \mathrm{C}$. After 24 hours of incubation, the culture was 
transferred to MacConkey's lactose agar (MLA) kept at $37^{\circ} \mathrm{C}$. After 24 hours of incubation the pure colonies were stained with Gram's stain for microscopic examination. Respective cultures were identified on the basis of standard criteria. Organisms giving pink coloured colonies on MLA were also cultured on eosin methylene blue agar (EMB). Cultures giving pale-yellow coloured colonies on MLA were also identified. All cultures were subjected to various biochemical tests.

\section{Biochemical tests}

E.coli and Salmonella were characterized on the basis of biochemical tests according to standard procedure described by Carter et al., (1994). E.coli and Salmonella isolates were subjected to Indole test, Methyl red test, Voges Proskauer test, Citrate utilization test (IMViC pattern).

\section{Parasitological examination}

Scrapings were taken from suspected cases and examined by direct wet mount smear.

\section{Results and Discussion}

The present study was carried to study occurrence and mortality patterns of poultry diseases in various parts of Jammu. Occurrence and mortality pattern of diseases at different farms is given in Table 4.1. The cumulative strength of birds in the farms was 564,753.Necropsy was conducted on representative carcasses of 632 birds. Different diseases/pathological conditions affecting broiler population in and around Jammu were colibacillosis, omphalitis, salmonellosis, IBD, coccidiosis, haemorrhages in proven triculus, caseous nodules in lungs, hepatotoxicity, gout, ascites, internal haemorrhage, fatty liver syndrome, nonspecific enteritis and nonspecific liver ailments. In cases where haemorrhages in proven triculus were seen, occurrence of Newcastle disease/avian influenza was suspected. Likewise in cases where caseous nodules were seen, brooder pneumonia was suspected.

In our study occurrence of colibacillosis $(24.16 \%)$ was maximum followed by that of IBD (7.13\%), omphalitis (6.79\%), salmonellosis (5.36\%), nonspecific enteritis (4.29\%), coccidiosis $(2.22 \%)$, haemorrhages in proventriculus $(1.67 \%)$, gout $(1.44 \%)$, hepatotoxicity $(1.42 \%)$, ascites $(1.14 \%)$, fatty liver syndrome $(1.03 \%)$, caseous nodules in lungs $(0.75 \%)$ and non specific liver ailments (0.50\%).However, Singh et al., (2003) found the occurrence of omphalitis, aflatoxicosis, colibacillosis, coccidiosis, aspergillosis, IBD and gout in Punjab to be much lower at $0.44 \%, 0.41 \%, 0.39 \%, 0.16 \%, 0.14 \%, 0.08 \%$ and $0.06 \%$. Incidence of omphalitis, colibacillosis, IBD, necrotic enteritis, Newcastle disease and brooder pneumonia as $13.40 \%, 11.11 \%, 10.58 \%, 6.35 \%, 4.59 \%$ and $3.70 \%$, respectively from birds in Assam was recorded by Borah et al., (2017). Ahmed et al., (2009) however, found the occurrence of colibacillosis IBD, omphalitis, and coccidiosis in Bangladesh to be much higher at $52.26 \%, 11.06 \%, 11.56 \%$ and $4.52 \%$, respectively. Similarly, Islam et al., (2003) in Sylhet region of Bangladesh recorded a higher occurrence of all the above mentioned diseases except that of colibacillosis which at5\% was found to be less than present study. Ahmed et al., (2012) reported IBD 29.37\% to be the most prevalent in broilers followed by colibacillosis $18.61 \%$ and coccidiosis $17.38 \%$ in district Poonch Azad J\&K.

The maximum mortality was caused by colibacillosis $(8.33 \%)$ followed by IBD $(5.97 \%)$, haemorrhages in proventriculus $(5.52 \%)$, omphalitis (4.54\%) followed salmonellosis $(3.66 \%)$, non specific enteritis 
(3.36\%), non specific liver ailments (3.03\%), hepatotoxicity $(2.95 \%)$, caseous nodules in lungs $(2.00 \%)$, coccidiosis $(1.69 \%)$, ascites $(1.12 \%)$, gout $(0.77 \%)$ and fatty liver syndrome $(0.41 \%)$.Similarly, Itoo et al., (2013) recorded occurrence of colibacillosis, Newcastle disease, aspergillosis, gout and ascites with respective mortalities of $6.4 \%$, $13.7 \%, 7.0 \%, 8.7 \%$ and $9.3 \%$ in and around Srinagar. However, Singh et al., (1998) reported that maximum mortality was caused by omphalitis (1.29\%) followed by IBD $(0.86 \%)$, coccidiosis $(0.56 \%)$, colibacillosis $(0.32 \%)$ and fowl typhoid $(0.23 \%)$ in Punjab. Mahajan et al., (1994) in Hisar, observed that the maximum mortality was caused by fowl typhoid $10.54 \%$ followed by colibacillosis $8.88 \%$, miscellaneous diseases like gout, ascites $(8.05 \%)$, brooder pneumonia $(7.69 \%)$, coccidiosis $(6.85 \%)$ and Newcastle disease $(6.03 \%)$.

Table.1 A summary of occurrence and mortality pattern of diseases at 200 different farms surveyed

\begin{tabular}{|c|c|c|c|c|c|c|c|}
\hline S. & $\begin{array}{c}\text { Confirmed and } \\
\text { Nuspected } \\
\text { pathological } \\
\text { conditions }\end{array}$ & $\begin{array}{c}\text { Total } \\
\text { no. of } \\
\text { flocks }\end{array}$ & $\begin{array}{c}\text { Total } \\
\text { number } \\
\text { of birds }\end{array}$ & $\begin{array}{c}\text { Total } \\
\text { number of } \\
\text { morbid } \\
\text { birds } \\
\text { (app.) }\end{array}$ & $\begin{array}{c}\text { Total } \\
\text { number } \\
\text { of dead } \\
\text { birds }\end{array}$ & $\begin{array}{c}\text { Occurrence } \\
(\mathbf{\%})\end{array}$ & $\begin{array}{c}\text { Mortality } \\
(\mathbf{\%})\end{array}$ \\
\hline $\mathbf{1 .}$ & Colibacillosis & 82 & 180753 & 126000 & 10500 & 24.16 & 8.33 \\
\hline $\mathbf{2 .}$ & Omphalitis & 17 & 53900 & 36685 & 1666 & 6.79 & 4.54 \\
\hline $\mathbf{3 .}$ & Salmonellosis & 24 & 50600 & 29250 & 1071 & 5.36 & 3.66 \\
\hline $\mathbf{4 .}$ & IBD & 22 & 44800 & 38000 & 2272 & 7.13 & 5.97 \\
\hline $\mathbf{5 .}$ & Coccidiosis & 06 & 21600 & 12380 & 210 & 2.22 & 1.69 \\
\hline $\mathbf{6 .}$ & $\begin{array}{c}\text { Haemorrhages in } \\
\text { proventriculus }\end{array}$ & 03 & 11500 & 8980 & 496 & 1.67 & 5.52 \\
\hline $\mathbf{7 .}$ & $\begin{array}{c}\text { Caseous nodules } \\
\text { in lungs }\end{array}$ & 03 & 11000 & 4200 & 84 & 0.75 & 2.00 \\
\hline $\mathbf{8 .}$ & Hepatotoxicity & 06 & 13000 & 7830 & 231 & 1.42 & 2.95 \\
\hline $\mathbf{9 .}$ & Gout & 05 & 24500 & 8100 & 63 & 1.44 & 0.77 \\
\hline $\mathbf{1 0 .}$ & Ascites & 07 & 17200 & 6400 & 72 & 1.14 & 1.12 \\
\hline $\mathbf{1 1 .}$ & Non specific & 16 & 35600 & 23485 & 791 & 4.29 & 3.36 \\
\hline $\mathbf{1 2 .}$ & Fatty liver & 04 & 42500 & 5800 & 24 & 1.03 & 0.41 \\
\hline $\mathbf{1 3 .}$ & $\begin{array}{c}\text { Non specific liver } \\
\text { ailments }\end{array}$ & 02 & 4700 & 2765 & 84 & 0.50 & 3.03 \\
\hline $\mathbf{1 4 .}$ & $\begin{array}{c}\text { Internal } \\
\text { haemorrhage }\end{array}$ & 03 & 36400 & - & 05 & - & \\
\hline & Total & 20 & 564753 & 309875 & 17569 & 57.98 & 5.66 \\
\hline & & & & & & \\
\hline
\end{tabular}


Table.2 Age wise distribution of disease conditions

\begin{tabular}{|c|c|l|}
\hline Sr. No. & $\begin{array}{c}\text { Age of birds } \\
\text { (weeks) }\end{array}$ & \multicolumn{1}{|c|}{ Pathological conditions } \\
\hline $\mathbf{1 .}$ & $0-1$ & Omphalitis (E.coli and Salmonella) and salmonellosis \\
\hline $\mathbf{2 .}$ & $1-2$ & $\begin{array}{l}\text { Colibacillosis, omphalitis, salmonellosis, caseous nodules in lungs, } \\
\text { gout and non specific enteritis. }\end{array}$ \\
\hline $\mathbf{3 .}$ & $2-3$ & $\begin{array}{l}\text { Colibacillosis, salmonellosis, haemorrhages in proventriculus, ascites, } \\
\text { gout, internal haemorrhage, fatty liver syndrome, non } \\
\text { specificproventriculitis and enteritis. }\end{array}$ \\
\hline $\mathbf{4 .}$ & $3-4$ & $\begin{array}{l}\text { Ascites, colibacillosis, IBD, coccidiosis, Hepatotoxicity, fatty liver } \\
\text { syndrome, non specific liver ailmentsandnon specific enteritis. }\end{array}$ \\
\hline $\mathbf{5 .}$ & $4-5$ & Colibacillosis, IBD, Hepatotoxicity andnonspecificenteritis. \\
\hline
\end{tabular}

Buragohainand Kalita (2010) observed that ascites syndrome (34.3\%) was main cause of mortality followed by colibacillosis $(19.23 \%)$, omphalitis (12.18\%) and caecal coccidiosis $(8.33 \%)$ in Mizoram. Lalrintlunga and Baruah (1993) from Assam reported that highest mortality was due to Newcastle disease $(25.9 \%)$, coccidiosis $(15.7 \%)$, colisepticaemia (14.6\%), aflatoxicosis (10.5\%) and omphalitis (5.8\%). Anjaneyulu et al., (1998) reported that colisepticaemia (13.4\%) followed by IBD $(9.1 \%)$, coccidiosis $(7.0 \%)$ and ascites $(6.78 \%)$ were the major causes of mortality in broilers in Prakasam district of Andhra Pardesh.

Pugashetti and Shivakumar (2007) observed that maximum deaths in broiler birds in an organised poultry farm of Karnataka were caused by pneumonia (29.60\%), enteritis (27.73\%), ascites (7.22\%) and coccidiosis (2.51\%). Reddy and Reddy (1991) observed the mortality pattern in broilers was maximum due to coccidiosis $(21.51 \%)$ followed by Newcastle disease $(11.8 \%)$ and enteritis (1.95\%). However, Ahmed et al., (2009) reported that highest mortality was due to colibacillosis $(52.26 \%)$ followed by omphalitis (11.56\%), IBD (11.06\%), coccidiosis $(4.52 \%)$, mixed infection of IBD and coccidiosis $(1.51 \%)$ and salmonellosis $(1.01 \%)$ at Kapasia in Gazipur district.
Disease conditions recorded in different age groups is given in Table 4.2.In birds $0-1$ week of age, the pathological conditions recorded were omphalitis and salmonellosis. colibacillosis, omphalitis, salmonellosis, caseous nodules in lungs, gout and non specific enteritis were seen in birds of 1-2 weeks of age. However, colibacillosis, salmonellosis, haemorrhages in proventriculus, ascites, gout, internal haemorrhage, fatty liver syndrome, proventriculitis, gizzard erosions and nonspecific enteritis were major conditions observed in 2-3 weeks old birds. Birds in 3-4 weeks of age were found to be affected with ascites, colibacillosis, coccidiosis, IBD, hepatotoxicity, fatty liver syndrome, non specific liver ailments, non specific enteritis whereas 4-5 week old birds were found to be affected with colibacillosis, IBD, hepatotoxicity andnon specificenteritis (Table 4.2).

In conclusion, colibacillosis was most common disease in broiler chickens affecting all age groups and prevalent in all seasons with an occurrence of $24.16 \%$ and caused $8.33 \%$ mortality. Other diseases or pathological conditions affecting the broilers were IBD, omphalitis, salmonellosis, nonspecific enteritis, coccidiosis, haemorrhages in proventriculus (NCD/Avian influenza suspected), gout, nephro- 
hepatotoxicity, ascites, fatty liver syndrome, presence of caseous nodules in lungs and non specific liver ailments. Implementations of better managemental practices are recommended to minimize disease occurrence and the consequent economic losses due to morbidity and mortality in broiler birds. The information generated in present study should serve as base line data for future studies to determine molecular prevalence of various diseases in broilers of Jammu.

\section{References}

Ahmed, I., Anjum, M.S. and Hanif, M. 2012. Prevalence of poultry diseases at high altitudes of district Poonch Azad Jammu \& Kashmir. Pakistan Journal of Science, 64(4): 334.

Ahmed, M.S., Sarker, A. and Rahman, M.M. 2009. Prevalence of infectious diseases of broiler chickens in Gazipur district. Bangladesh Journal of Veterinary Medicine, 7(2): 326-331.

Ahmed, M.S., Sarker, A. and Rahman, M.M. 2009. Prevalence of infectious diseases of broiler chickens in Gazipur district. Bangladesh Journal of Veterinary Medicine, 7(2): 326-331.

Anjaneyulu, Y., Babu, N.S. and James, R.M. 1998. Mortality pattern in broilers in Prakasam district (Andhra Pradesh). Indian Journal of Veterinary Pathology, 22(1): 44-46.

Borah, M.K., Islam, R., Sarma, M., Mahanta, J.D. and Kalita, N. 2017. Prevalence and seasonal variation of certain microbial diseases in Kamrup and Kamrup (Metro) Districts of Assam. International Journal of Chemical Studies, 5(3): 724-726.

Buragohain, R. and Kalita, G. 2010. Assessment of mortality pattern of broiler under intensive system of management in Mizoram. Tamilnadu Journal of Veterinary \& Animal
Sciences, 6(5): 239-241.

Carter, G.R., Quinn, P.J., Carter, M.E. and Markey, B. 1994. Clinical Veterinary Microbiology. pp. 209-236.

Cruickshank, R., Duguid, J.P., Marsion, B., Pand Swain, R.H.A. 1975. In: MedicalMicrobiology Vol II $12^{\text {th }}$ ed. IBM, New Delhi.

Islam, M.R., Das, B.C., Hossain, K., Lucky, N.S. and Mostafa, M.G. 2003. A study on the occurrence of poultry diseases in Sylhet region of Bangladesh. International Journal of Poultry Science, 2(5): 354-356.

Itoo, F.A., Kamil, S.A., Mir, M.S., Baba, O.K., Dar, T.A. and Darzi, M.M. 2013. Occurrence and pathology of diseases with associated respiratory tract affections in commercial broiler chickens reared in Kashmir. Journal of Research,15(1): 23-34.

Lalrintluanga, C. and Baruah, G.H. 1993. Mortality pattern in broilers in Assam. Indian Journal of Veterinary Pathology, 17(2): 126-128

Luna, L.G. 1968. Manual of Histologic Staining Methods of the Armed Forces Institute of Pathology, (ed. $3^{\text {rd }}$ ). McGraw Hill Book Company, New York.

Mahajan, N.K., Jindal, N. and Kulshreshtha, R.C. 1994. Major broiler diseases in some parts of Haryana. Indian Journal of Animal Sciences, 64(11): 1118-1122.

Mehta, R., Nambiar, R.G., Delgado, C.L. and Subramanyam, S. 2003. Annex II: Livestock industrialization project: Phase II-policy, technical and environment determinants and implications of the scaling-up of broiler and egg production in india. IFPRIFAO Project, Food and Agricultural Organization of the United Nation, Rome, Italy, July24, 2003.

Pugashetti, B.K. and Shivakumar, M.C. 2007. Mortality incidence of various causative 
agents in an organised poultry farm. Karnataka Journal of Agricultural Sciences, 20(1): 187-188.

Reddy, P.R. and Reddy, A.R.M. 1991. Study on mortality pattern in broilers. Poultry Advisor, 24(5): 21-24.

Saif, Y.M. 2008. Disease of Poultry. $12^{\text {th }}$ Edition, Blackwell Publishing Ltd, Iowa.

Singh, G., Sharma, N.S., Jand, S.K. and Brar, R.S. 2003. Mortality pattern in broilers at selected farms in Punjab. Journal of Research,40(3): 452-455.

Singh, R.P. 1998. Aetiopathological studies of chick mortality with particular reference to bacterial infections. M.V.Sc. thesis, Punjab Agricultural University, Ludhiana, India.

Thrusfield, M. 2005. Veterinary Epidemiology, Third edition, Blackwell Science Ltd., 53-65.

\section{How to cite this article:}

Navroze Sanhga, Shilpa Sood, A.K. Taku, Nawab Nashiruddullah, Shafiqur Rahman, Deep Shikha, Satuti Sharma and Sankalp Sharma. 2019. An Investigation on the Occurrence of Pathological Conditions Affecting Broilers in Jammu. Int.J.Curr.Microbiol.App.Sci. 8(08): 2351-2357. doi: https://doi.org/10.20546/ijcmas.2019.808.272 